to the underlying disease than to the treatment, and in these sick children risks must be taken. In supplementary or shortterm parenteral feeding, however, unnecessary risks are unjustifiable. Careful monitoring and strict aseptic control may reduce such risks to a minimum, but in every case the advantages of the treatment must clearly outweigh its hazards.

${ }^{1}$ Dudrick, S J, Rhoads, J E, and Vars, H M, Fortschritte der Parenteral Ernährung, 1967, 2, 16.

2 Wilmore, D W, and Dudrick, S J, Fournal of the American Medical Association, 1968, 203, 860 .

Wilmore, D W, et al, fournal of Pediatric Surgery, 1969, 4, 181.

' Filler, R M, et al, New England Fournal of Medicine, 1969, 281, 589.

Heird, W C, and Winters, R W, Fournal of Pediatrics, 1975, 86, 2 .

"Curry, C R, and Quie, P G, New England fournal of Medicine, 1971, $\mathbf{2 8 5}, 1221$.

' Wei, P, Hamilton, J R, and LeBlanc, A E, Canadian Medical Association, Journal, 1972, 106, 969

${ }^{8}$ Fox, H A, and Krasna, I H, Pediatrics, 1973, 52, 14.

${ }^{9}$ Paulsrud, J R, et al, American fournal of Clinical Nutrition, 1972, 25, 897.

1" Press, M, Hartop, P J, and Prottey, C, Lancet, 1974, 1, 597.

${ }^{11}$ Panter-Brick, M, European fournal of Intensive Care Medicine, 1976, 2,45 .

12 Wretlind, A, in Parenteral Nutrition, ed A W Wilkinson, p 160. Edinburgh, and London, Churchill Livingstone, 1972

${ }^{13}$ Borreson, H C, Coran, A G, and Knutrud, O, Annals of Surgery, 1970. 172, 291

$14 \mathrm{Kim}, \mathrm{S} \mathrm{H}$, and Rickham, P P, Zeitschrift für Kinderchirurgie und Grenzgebiete, 1972, 11, 277.

${ }^{15}$ Borreson, H C, Knutrud, O, and Vaage, S, Progress in Pediatric Surgery, $1975,8,49$.

16 Winick, M, Rosso, P, and Brasel, J A, Nutritio et Dieta, 1972, 17, 60.

${ }^{17}$ Davis, J, and Dobbing, J, (eds), Scientific Foundations of Paediatrics. London, Heinemann, 1974

1s Filler, R M, and Coran, A G, Surgical Clinics of North America, 1976, $\mathbf{5 6}, 395$.

19 Johnson, J C, Albritton, W L, and Sunshine, P, Pediatrics, 1972, 81, 154.

20 British Medical fournul, 1973, 1, 307.

21 Bryan, H, et al, Pediatrics, 1976, 58, 787.

$2: 2$ Kwiterovich, P O, Pediatrics, 1974, 53, 455.

23 Lipson, A H, Pritchard, J, and Thomas, G, Lancet, 1974, 2, 1462.

${ }^{24}$ Panter-Brick, M, Wagget, J, and Dale, G, Lancet, 1975, 1, 857.

\section{Learnt voluntary control of heart rate and rhythm}

Normal people become aware of the autonomic control of the heart and blood vessels only when this becomes extreme, when it has ceased to be purely automatic-for example, tachycardia of fear or the hypotension of a faint induced by the sight of blood. Nevertheless, there are so many ways that this automatic regulation can be reset by the interference of other parts of the nervous system - the fall in heart rate and blood pressure during sleep, the rise while doing mental arithmetic-that it is autonomic only in the sense that it is not usually under direct conscious control. Since activity in the higher centres so profoundly influences the control systems, many investigators have speculated that these could be brought under voluntary control if the individual was provided with a signal recording the state of the system. The use of such a signal has become known as biofeedback.

We now have convincing evidence that trained individuals can achieve small, short-term changes in both heart rate and blood pressure if they are provided with a visual or auditory signal to show them the results of their efforts. Weiss and Engel ${ }^{1}$ first used biofeedback to treat a group of eight patients with cardiac arrhythmia, five of whom learnt to decrease the frequency of the abnormal beats. More recently Pickering and Miller ${ }^{2}$ used the technique to investigate and treat two patients with frequent premature ventricular contractions. They justified the time spent on this approach on two grounds: firstly, that the drugs commonly used to treat premature ventricular contractions are potentially dangerous myocardial depressants; and, secondly, that drug treatment is inappropriate because of the evidence that the nervous system can influence the onset and disappearance of premature ventricular contractions. ${ }^{3}$ Certainly the frequency of premature beats falls during sleep and increases during psychological stress. ${ }^{45}$

Their first patient had bigeminal rhythm and was provided with an oscilloscope signal from a cardiac monitor. Gradually, over 25 training sessions spread over several months, he acquired some conscious control. Eventually he was in sinus rhythm for $3 \%$ of the time when he was just resting and $27^{\circ}$ o of the time when he was trying consciously to influence the rhythm. This patient's suppression of bigeminal rhythm was associated with an increase in heart rate, though it was not wholly due to this change. The second patient had premature ventricular beats and was provided with a ratemeter signal. He quite quickly learnt to increase his heart rate by $20-25$ beats minute by conscious effort. Once he achieved a sinus rate of about 117 beats minute the arrhythmia was usually suppressed.

The use of biofeedback to control cardiac arrhythmias raises two questions. Firstly, how does the patient achieve the effect? Secondly, is the effect large enough and well enough sustained to be of any therapeutic value? In both the cases described an increase in rate seems to have been important, though not the sole explanation. Clearly if the method is to be of practical value the patient must be able to apply the training he has received in the laboratory with the biofeedback signal when he no longer has that signal available. The second of Pickering and Miller's patients seemed to be able to do this, but the first could not. Possibly, too, the increase in the heart rate achieved to suppress arrhythmias might have had other adverse consequences if it had been maintained over long periods. Just as investigators who make therapeutic claims for new drugs have to prove their safety and efficacy in long-term use, so must advocates of biofeedback.

\footnotetext{
1 Weiss, T, and Engel, B T, Psychosomatic Medicine, 1971, 33, 301.

2 Pickering, T G, and Miller, N E, British Heart fournal, 1977, 39, 152.

${ }^{3}$ Mauck, H P, and Hockman, C H, American Heart fournal, 1967, 74, 96.

${ }^{4}$ Lown, B, et al, Circulation, 1973, 48, 691.

${ }^{5}$ Pickering, T, and Gorham, G, Lancet, 1975, 1, 252.
}

\section{Motorcyclists' injuries and crash helmets}

Motorbikes are dangerous: a motorcyclist is eight times more likely to be fatally injured than the occupant of a car per unit distance travelled. ${ }^{1}$ Despite this, the number of motorcycles on our roads is rising and probably will continue to do so as the cost of transport goes up. Accompanying the increase in motorcycle use the Royal Society for the Prevention of Accidents ${ }^{2}$ has noted an increase in the number of casualties among users of "powered two-wheelers" in the first nine months of 1976-part of a general upward trend over the last five years. The implications of this trend are serious, affecting not only motorcyclists but also other road users; clinicians concerned with patient care; design engineers of safety equipment, such as crash helmets; and the rest of the community, who share the costs (nowadays put at around 
$£ 40000$ ) of each fatal accident. In the third quarter of 1976 there were 332 accidental deaths among two-wheeler road users: eight were riding motor scooters; 34 mopeds; and 290 motorbikes. In that same period there were 4468 serious injuries from the use of motorcycles. Overall, every day three motorcyclists are killed and 50 seriously injured; the daily total from all types of road accident is 18 fatal and 230 serious injuries

A two-county survey of 483 motorcycle accidents conducted by the Transport and Road Research Laboratory in $1974^{3}$ showed the high proportion $\left(63^{\circ}{ }_{0}\right)$ of young people (aged 16-19) affected and the predominance of youths $\left(91^{\circ}{ }_{0}\right)$ a terrible waste of youthful vitality. Two-thirds of the accidents were on machines with engines of under $300 \mathrm{cc}$ capacity, including one-third under $50 \mathrm{cc}$. Most collisions were frontal and occurred at road junctions, with an impact speed differential of $3: 1$ between the motorcyclist and the other vehicle in the collision. The same survey showed that most injuries were to the limbs, with twice as many legs as arms damaged. A relatively high proportion $\left(34^{\circ}{ }_{0}\right)$ of the moderate injuries included trauma to the head; for fatal accidents Sevitt ${ }^{4}$ has put the incidence of head injury as high as $64^{\circ}{ }^{\circ}$, while Gögler ${ }^{5}$ has shown that $37^{\circ} \%$ of injured motorcyclists have multiple injuries.

What may we learn from these findings? The lessons come under three headings: avoidance of the accident, prevention of injury, and improved patient care. In accident avoidance one important factor is the use of aids to make the motorcyclist conspicuous. Thus a fluorescent orange over-waistcoat with reflective markings makes the rider stand out in a crowd, while daytime use of the front and rear lights (which is becoming increasingly popular) also helps. Prevention of injury must initially centre on the use of crash helmets, and, a before-and-after study ${ }^{6}$ has been made of the effects of legislation passed in Queensland, Australia, in 1970 to make this compulsory. As shown in other surveys, a big rise in helmet usage led to a substantial fall in the incidence of head injury. Furthermore, with this widespread use inevitably differences in helmet design and protection have begun to emerge, and Vaughan ${ }^{7}$ has recently described differences between the original standard helmet (resembling a building site hat), the jet helmet (resembling a pilot's helmet), and the newer full-face helmet, which extends the protective shell to cover the lower jaw. He found that riders wearing the jet helmet design were two to three times more likely to receive facial injury than those wearing full-face helmets. Such injuries may not only disfigure the victim for life but they also pose an immediate threat from the combination of unconsciousness and airway impairment. Wearing a full-face helmet was not associated with a greater chance of a crash. The move towards improved protection from injury to the head has been paralleled by recent developments to protect the legs. Bothwell ${ }^{8}$ has produced such a design and it should be only a matter of time before the principle is widely adopted.

\footnotetext{
${ }^{1}$ Medical fournal of Australia, 1977, 1, 121.

2 Care on the Road. February, London, RoSPA, 1977.

3 Whitaker, J, Motor Cycle Safety-Accident Survey and Rider Injuries, supplementary report 239. Crowthorne, Transport and Road Research Laboratory, 1976.

${ }^{4}$ Sevitt, S, Injury. British Fournal of Accident Surgery, 1972 73, 4, 281.

5 Gögler, E, Documenta Geigy-Series Chirurgica-Road Accidents. Manchester, Geigy, (UK), 1965

${ }^{6}$ Jamieson, K G, and Kelly, D'A, Medical fournal of Australia, 1973 2, 806.

7 Vaughan, R G, Medical fournal of Australia, 1977, 1, 125.

${ }^{8}$ Care on the Road. London, RoSPA, December, 1976.
}

\section{Deaths due to drug treatment}

Prevention of deaths from external causes implies a balance of risks against gains: banning rock climbing, alcohol, motor vehicles, or aeroplanes on the grounds of their undoubted threat to human life would make the world less interesting and enjoyable, albeit safer. Recently the Cassandras of the national press have turned their attention towards various medical hazards, and considerable play has been made on the toxicity of drugs such as practolol and techniques such as vaccination against whooping cough. Pessimism about drug treatment is not, however, confined to journalists; indeed, in 1971 one of America's distinguished clinical pharmacologists alleged" that in that country "the economic consequences of drug reactions are staggering: one-seventh of all hospital days is devoted to the care of drug toxicity at an estimated annual cost of $\$ 3000 \mathrm{~m}$." More recently another group claimed ${ }^{2}$ that drugs were resulting in the deaths of up to 140000 Americans annually. Clearly if this were true the balance has tipped over and our treatment needs total revision: but in fact these claims are grossly exaggerated.

No matter how carefully the clinical course is reviewed, it is often difficult or impossible to decide whether a particular patient died solely as a consequence of his or her underlying disorder or in part from the effects of drug administration. Good quality studies of the prevalence of drug-related deaths are rare and have usually been confined to highly selected areas: most have concerned medical inpatients in university hospitals-a select group of severely ill patients. Extrapolation to the whole range of hospital treatment from information based on such narrow observations is clearly unjustified and has been strongly condemned. ${ }^{34}$

Several recent studies of drug-related deaths have found that about 1 per 1000 medical inpatients die at least in part as a consequence of drug treatment. ${ }^{5}$ One of these studies ${ }^{6}$ came from the Boston Drug Surveillance Program and is of particular interest since it reviewed data from selected hospitals in seven countries. The message of this study is clear: most of the patients who died from drug therapy (in part at least) were suffering from severe, terminal illness such as cancer, leukaemia, pulmonary embolism, and cirrhosis. Viewed retrospectively, only six out of 24 deaths occurring in 26500 consecutive patients could have been prevented, and in only three cases did death result from treatment of patients who otherwise were only mildly unhealthy. The prevalence of preventable deaths in this group of medical inpatients was 1 per 10000 , and the drugs responsible were predominantly intravenous fluids and potassium chloride.

Information on patients other than medical inpatients is sparse. Armstrong and his colleagues ${ }^{7}$ in the Boston Group reported that drug-related deaths occurred in only two of a carefully defined group of 10280 surgical inpatients. In both cases death was attributed to haemorrhage as a result of heparin administration to elderly women-a group known to be at particularly high risk of toxicity from this drug. ${ }^{8}$

Information from outpatient sources is understandably much more difficult to come by, and only details from spontaneous reports to agencies are available. These agencies are well known to underestimate the true frequency of side effects, but this may be less true of Sweden, where such reports are mandatory, than of other countries. The pattern is similar in Sweden ${ }^{9}$ and in the United Kingdom. ${ }^{10}$ In both countries haematological, thromboembolic, and anaphylactic events account for most drug-related deaths in outpatients. 